\title{
STUDENTS' PERCEPTION OF GEOGRAPHY ONLINE COURSES AT THE UNIVERSITY OF BANJA LUKA DURING THE COVID-19 PANDEMIC
}

DOI: https://doi.org/10.18509/AGB218-3117p

UDC: 378.018.43:004]:91\}:616.98:578.834]-036.21(497.6)

\author{
Aleksandra Petrašević, Mlađen Trifunović
}

University of Banja Luka, Faculty of Natural Sciences and Mathematics, Banja Luka

(The Republic of Srpska), Bosnia and Herzegovina,

corresponding author:

submitted: 05.03.2021

accepted: 06.05.2021

published: 05.09.2021

\begin{abstract}
Even though distance learning via different e-platforms was introduced decades ago, it was only when the COVID19 pandemic emerged that it became a globally spread form of education. There has been controversy about this type of learning and its corresponding platforms and the authors believe that the whole process should be assessed. The paper outlines result of the analysis of students' perception of geography courses held online via the Google Classroom platform in the school year of 2019/2020. A questionnaire survey was conducted among the first cycle students at the departments of Geography and Spatial Planning at the Faculty of Natural Sciences and Mathematics at the University of Banja Luka. The survey was conducted based on the adapted model used by Bolton, Smidt and Li [1]. The aim of the survey was to discover how students evaluated the performance of four primary aspects of distance learning: the quality of teaching process, the adequacy of e-platforms, the teachers' assistance and the quality of the teaching content.
\end{abstract}

Keywords distance learning, geography, COVID-19, students' perception.

\section{INTRODUCTION}

Since the organization of any type of the teaching process is impossible without the so-called didactic pentagram [2], [3] the advantages and shortcomings of distance learning must encompass students, teachers and the teaching content (classic triad) as well as the teaching process management and the ownership structure. It is the ownership structure that benefits most from e-learning due to much lower teaching costs when compared with regular "face-to-face" classes. According to Kruse [4] there are multiple advantages of e-learning for all of the participants in the process. The same author claims that online classes fundamentally decrease the time frame necessary for the adoption of the teaching content (60 percent) and that the acquirement and applicability of the content increase fourfold in contrast to the non-electronic types of learning. These advantages refer directly to the teaching process outcomes, but there are also organizational advantages such as the constant availability of the content regardless of the students' location, adaptability to individual learners and their schedule, and the encouragement of lifelong learning, as well as the advantages concerning social inclusion of specific social groups such as students with special needs and socio-phobic and stigmatized individuals [4], [5], [6], [7], [8].

There is a great body of work focusing on shortcomings of the e-learning organization. Many authors [4], [9] deem that the greatest shortcomings of e-learning are: a) the reduction of non-mediated social interaction among the teaching process participants which might lead to social isolation, and b) the excessive reliance on the digital communication technology during the teaching process. Wang and Newlin [9] believe that the digitally mediated communication is characterized by asynchronicity, which largely reduces the amount and quality of interpersonal interaction. The current e-learning practice may eventually cause a loss of awareness of non-mediated interaction pertinence, which may result in gradual isolation. When it comes to other possible negative consequences of the e-learning organization, Kruse 
[4] points out the matter of availability of necessary devices to all the participants in the process and wonders whether e-learning may actually provide the desirable learning outcomes, taking into account the technical demands and software compatibility. The emergence of COVID-19 pandemic has put all these dilemmas aside as e-learning becomes the only available type of educational process organization. An adequate response of all schools worldwide necessarily meant a temporary abandonment of physical presence in classes, which required communication among students, parents and teachers, and the availability of teaching materials via different e-platforms. On March 20th 2020, The University of Banja Luka adopted a Decision to organize the online teaching process via the Google Classroom platform at all its departments in the summer semester of 2019/2020 school year. We should point out that e-learning was not a common practice at our university prior

\section{MATERIALS AND METHODS}

The evaluation of e-learning structure and quality is performed by: a) analyzing the characteristics of elearning itself, i.e., the planned outcomes of the learning process, and b) comparing it with the socalled traditional organization of the teaching process which represents a starting point for the evaluation of e-learning, especially if it is conducted at the first cycle of university studies. Different authors have different opinions about the planned outcomes of distance learning but there are still some general aspects of the distance learning evaluation that can be singled out as follows: the active interaction and engagement, the efficient planning and design of the curriculum, and the adequate student support. These aspects are largely compatible with the traditional learning organization so a question emerges which categories should be studied in order to obtain results relevant for e-learning. The assessment of the teaching content is insufficient. The organization of distance learning demands specific quality aspects which should be clearly stated. According to Nandi et al. [10] there are three aspects of evaluation: the teaching content, the interaction quality and the objective assessment.

Nevertheless, in order to evaluate this type of learning, it is crucial to examine technical (eplatforms and their properties), demographic and curriculum aspects. There is also the matter of students' motivation and activation in regard to elearning, which greatly depends on students' general perception of computer-mediated communication and distance learning. A questionnaire survey was conducted among the first cycle students at the departments of Geography and to the pandemic, except the teacher-student communication via e-mail.

Besides Google Classroom, the market offers other platforms such as Moodle (used at the University of East Sarajevo - the second public university in the Republic of Srpska) and communication tools such as Jitsi Meet and Zoom. Google Classroom was the platform of choice at our university as it was recommended by the Ministry of Scientific and Technological Development, Higher Education and Information Society, the body of authority for our university. The reasons why the Ministry selected this platform were the availability (the University uses the Google mail service), simple usage and service free of charge. The tools and programs used within the Google Classroom platform were the communication tools (Gmail, Hangouts, Calendar, Google+, Disk Drive, Doc), data storage tools (Drive) and presentation tools (Docs, Sheets, Forms, Slides, Sites).

Spatial Planning after the semester was completed. The questionnaire was designed in line with the model presented by Bolton et al. [1], comprising four sections used to perform the evaluation. The questionnaire was available in the electronic form. The first section examined students' opinions about the quality (How would you generally evaluate the conducted e-learning?) of the teaching content during geography online courses based on the following categories: the scope of the teaching content, the degree of students' activation in comparison with regular classes, the applicability of knowledge and skills gained, and sensitivity to different learning styles. The second section covered questions (Do you think that the Google Classroom platform was adapted to the needs of studying?) regarding the e-platform and its suitability for e-learning (Google Classroom), and the third section covered questions (How would you generally evaluate the teachers' and teaching assistants' roles in e-learning?) about the teachers' engagement and the interaction among all the participants in the process. The aim of the fourth section was to evaluate the quality of the teaching content (How would you generally evaluate the quality of the teaching content during e-learning?), its adequacy for e-learning and differences between the e-learning teaching content and the content used in regular classes. (See Appendix for a complete list of the questions asked). Students' general perception of the distance learning quality was measured mostly in 3 or 5 point rating scales. Each section provided space for additional students' opinions. 


\section{RESULTS}

The questionnaire was distributed among 66 students, $84 \%$ of whom (56 students) participated in the survey by providing their answers. The percentage of students who took part in the survey was almost equal at both departments: $87.88 \%$ at the Geography Department and $87.10 \%$ at the Spatial Planning Department.

Generally speaking, students rated the quality of online courses at both departments as good and average $-85.3 \%$. Still, there are disparities between students at the two departments as students of Geography tend to have better perception of online courses in comparison with Spatial Planning students. More than half of Spatial Planning students $(55.6 \%)$ rated the courses as average and less than third rated them as good $(29.6 \%)$. On the other hand, $62.1 \%$ of Geography students rated the courses as good (Table 1). The ratings clearly indicate that there is a need for the improvement of the distance learning process. Hence, it is crucial to analyze specific sections of the quality evaluation questionnaire. In line with the used methodology, different sections cover sets of questions referring to the teaching process organization, clear instructions, level of interaction among students, applicability of knowledge and skills, encouragement of spatial thinking, the scope and depth of the teaching content, the level of students' activation in comparison with regular classes, and sensitivity to different learning styles. All these answers were rated in line with a 3-point rating scale (excellent, good, poor). Eventually, students were provided with an empty slot to enter their own opinions regardless of these sections.

Table 1. General rating of online courses quality during COVID-19 pandemic as perceived by Geography and Spatial Planning students

\begin{tabular}{|c|c|c|c|c|c|}
\hline Course quality & excellent & good & average & fair & poor \\
\hline Geography & 3.4 & 62.1 & 24.1 & 10.4 & 0 \\
\hline Spatial Planning & 3.7 & 29.6 & 55.6 & 11.1 & 0 \\
\hline TOTAL & 3.6 & 46.4 & 39.3 & 10.7 & 0 \\
\hline
\end{tabular}

Tabel 2. Students' perception of specific aspects of the distance learning quality during COVID-19 pandemic

\begin{tabular}{|l|c|c|c|}
\hline Scope of the teaching content & excellent & good & poor \\
\hline Geography & 20.7 & 41.4 & 37.9 \\
\hline Spatial Planning & 22.2 & 37.1 & 40.7 \\
\hline TOTAL & 21.4 & 39.3 & $\mathbf{3 9 . 3}$ \\
\hline Spatial thinking encouragement & \multicolumn{3}{|l|}{} \\
\hline Geography & 27.6 & 55.2 & 17.2 \\
\hline Spatial Planning & 11.2 & 41.4 & 41.4 \\
\hline TOTAL & 19.6 & 50.0 & $\mathbf{3 0 . 4}$ \\
\hline Applicability of content & \multicolumn{3}{|l|}{} \\
\hline Geography & 10.3 & 55.2 & 34.5 \\
\hline Spatial Planning & 22.2 & 44.5 & 33.3 \\
\hline TOTAL & 16.1 & 50.0 & $\mathbf{3 3 . 9}$ \\
\hline Degree of students' activation & 20.7 & 41.4 & 37.9 \\
\hline Geography & 7.4 & 59.3 & 33.3 \\
\hline Spatial Planning & 14.3 & 50.0 & $\mathbf{3 5 . 7}$ \\
\hline TOTAL
\end{tabular}

Table 2 clearly indicates that most conspicuous shortcomings of distance learning refer to the scope and depth of the teaching content and its applicability, the level of students' activation, and finally, the encouragement of spatial thinking which is one of the key competencies of geo-spatial sciences. Almost $40 \%$ of students at both departments perceive the scope and depth of the teaching content as poor. Such perception is even more pronounced with Spatial Planning students $(40.7 \%)$, who believe that the teaching content and tasks during e-learning were not beneficial enough for the encouragement of spatial thinking. It was $41.4 \%$ of students that rated this aspect of learning as poor. Another pertinent aspect of distance learning emerging as problematic is the students' activation, which may be considered as unusual because students' activation is believed to be one of the advantages of distance learning [4].

Reasons for such students' perception may be found in their free answers regarding the course quality. A large number of students believe that the computermediated communication diminishes the essential value of the teaching process and becomes a secondary or partial activity within regular classes. Some of the answers provided by students are as follows:

We have lost the sense of real classes; without a direct contact there is a lack of responsibility and commitment when compared to regular classes, which results in partial efficiency on student's side; we feel that tasks we are given are some types of a homework which takes 10 minutes of our time; we feel that we are not real students because there are no regular lectures we are used to. 
Based on these answers, we may infer that the motivation problem is not exclusively rooted in distance learning but in the students themselves. It is noticeable that the students' motivation is not internal but is rather related to the external pressure. Responsibility and commitment are associated only to regular classes and the physical presence of an authority. Given the fact that the internet and information technologies are generally identified with entertainment and leisure, distance learning may have a negative impact on extrinsically motivated students unless the teaching materials are more adapted [11].
Another section of the questionnaire refers to the evaluation of the Google Classroom platform used as a distance learning medium. Most students have a neutral opinion on the platform. Around $45 \%$ of students believe that it is neither adapted nor unadapted to distance learning, whereas $16.1 \%$ of them assume that Google Classroom is poorly adapted to the online teaching process (Table 3). Spatial Planning students express more dissatisfaction with the platform than Geography students as $25.8 \%$ of them perceive Google Classroom as poorly adapted to their needs.

Table 3. Students' perception of the Google Classroom platform adaptability to distance learning during COVID-19 pandemic

\begin{tabular}{|l|c|c|c|}
\hline Degree of adaptability & Geography & Spatial Planning & TOTAL \\
\hline Very adapted & 0 & 0 & 0 \\
\hline Adapted & 41.4 & 37.1 & 39.3 \\
\hline Neutral & 51.7 & 37.1 & 44.6 \\
\hline Unadapted & 6.9 & 25.8 & 16.1 \\
\hline Very unadapted & 0 & 0 & 0 \\
\hline
\end{tabular}

Reasons of poor adaptability of the platform usually refer to: a) technical demands (stable connection, expensive internet service, problems of internet and computer infrastructure), and b) problems with the interactive aspects of the teaching process, especially while giving instructions for more complex teaching materials and practical tasks. The third section of the questionnaire refers to the students' perception of the teacher's role during online courses and the quality of interaction with both teachers and other students. The obtained results indicate that both teachers and teaching assistants performed their roles well. Their work was rated as either good $(60.7 \%)$ or excellent $(25 \%)$, which was a very positive rating. Not a single student rated a teacher's or a teaching assistant's work as poor and $14.3 \%$ of students rated it as fair.

Table 4. Students' perception of teachers' roles and interaction in online courses during COVID-19 pandemic

\begin{tabular}{|l|c|c|c|c|}
\hline Teacher's role and group interaction & excellent & good & fair & poor \\
\hline Usefulness of office hours & \multicolumn{4}{l|}{} \\
\hline Geography & 37.9 & 34.5 & 27.6 & 0 \\
\hline Spatial Planning & 25.9 & 40.8 & 33.3 & 0 \\
\hline TOTAL & 32.1 & 37.5 & 30.4 & 0 \\
\hline Availability of teachers and teaching assistants & \multicolumn{5}{l|}{} \\
\hline Geography & 37.9 & 37.9 & 24.2 & 0 \\
\hline Spatial Planning & 48.1 & 37.1 & 14.8 & 0 \\
\hline TOTAL & 42.9 & 37.5 & 19.6 & 0 \\
\hline Kindness of teachers and teaching assistants & \multicolumn{4}{|l|}{} \\
\hline Geography & 44.8 & 51.7 & 3.5 & 0 \\
\hline Spatial Planning & 37.1 & 40.7 & 22.2 & 0 \\
\hline TOTAL & 41.1 & 46.4 & 12.5 & 0 \\
\hline Connectedness with other students & \multicolumn{4}{|l|}{} \\
\hline Geography & 17.2 & 31.0 & 51.8 & 0 \\
\hline Spatial Planning & 14.9 & 40.7 & 40.7 & 3.7 \\
\hline TOTAL & 16.1 & 35.8 & 46.4 & 3.7 \\
\hline
\end{tabular}

Social interaction, availability of teachers and teaching assistants and their treatment of students are pertinent aspects of the teaching process, especially in states of emergency such as the COVID-19 pandemic. Teachers at both departments at the Faculty of Natural Sciences and Mathematics, University of Banja Luka, who were rated in the questionnaire, displayed a high level of flexibility and social sensitivity to students' needs. Their availability and kindness were perceived as excellent and good, $80.4 \%$, and $87.5 \%$ respectively (Table 4). Nevertheless, the interaction between teachers and students is not so strong if we consider the teaching process efficiency and the learning effects. The usefulness of online office hours is rated as fair by $37.5 \%$ of Spatial Planning students and $32.1 \%$ of Geography students. An explanation for the discrepancy between the good and fair teacherstudent communication may lie in the manner in 
which the Google Classroom platform was used. Students elaborated their ratings as follows:

All dilemmas we encounter are addressed via e-mail which makes it difficult for us to ask a question properly and get a clear answer in order to understand a specific topic; there are too many questions that teachers cannot answer through an email as clearly as they can in regular classes; it is more difficult to learn something only by reading presentations and texts; if the new semester is held online, I only hope it will be a "real" online course held by all teachers equally because, in my case, new lessons cannot be learned just through written communication. It is obvious that the e-mailmediated communication as a dominant model of interaction between teachers and students, is far poorer than a face-to-face dialogue, even in cases when the dialogue is computer-mediated [12]. Some of the students' explanations mentioned in the previous paragraph clearly point this out.

Table 5. The degree of interconnectedness among students in online courses during COVID-19 pandemic

\begin{tabular}{|l|c|c|c|c|}
\hline The degree of interconnectedness & very high & moderate & low & very low \\
\hline Geography & 17.2 & 31.0 & 51.8 & 0 \\
\hline Spatial Planning & 14.9 & 40.7 & 40.7 & 3.7 \\
\hline TOTAL & 16.1 & 35.7 & 46.4 & 1.8 \\
\hline
\end{tabular}

Table 6. Students' perception of the teaching content quality in online courses during COVID-19 pandemic

\begin{tabular}{|l|c|c|c|c|c|}
\hline Quality of the teaching content & excellent & good & average & fair & poor \\
\hline Geography & 20.7 & 37.9 & 37.9 & 3.5 & 0 \\
\hline Spatial Planning & 11.1 & 25.9 & 51.9 & 11.1 & 0 \\
\hline TOTAL & 16.1 & 32.1 & 44.6 & 7.2 & 0 \\
\hline
\end{tabular}

The sense of interconnectedness and affiliation to a group is crucial for the success of the teaching process and the psycho-social well-being of students, particularly after a long-term isolation due to the pandemic. Students' perception of interconnectedness indicates that the computermediated communication is unable to compensate for the students' social cohesion during regular studies. Eventually, there comes the loss of the group identity and the sense of interconnectedness and friendship. Most Geography students $(51,8 \%)$ believe that the degree of interconnectedness among them during distance learning was low (Table 5).

The fourth section of the questionnaire is particularly interesting as it provides us with a direct insight into students' perception of the scope, quantity and adequacy of the teaching content. Students at both departments agree that the scope of the teaching content they learned was not adequate. It was $73,4 \%$ of Spatial Planning students and $65,5 \%$ of Geography students who believed that the scope of the teaching content was too broad and that they were presented with too many materials over a short period of time, resulting in the accumulation of tasks.

The quality of the teaching materials sent to students via the Google Classroom platform was rated as

\section{CONCLUSION}

The conducted questionnaire survey offered a valuable insight into students' perception of online courses held during the COVID-19 pandemic. The obtained results may help us design guidelines in order to improve the quality of distance learning. We may infer that it was difficult for teachers to set average $(51.9 \%)$ and good $(25.9 \%)$ by Spatial Planning students, whereas Geography students had a slightly better opinion (Table 6).

Ratings of the teaching content quality are related to specific demands of specific subjects, which must be met in order to fully achieve courses' objectives. Some courses and their teaching content proved to be inadequate for distance learning. According to the students, the GIS course (Geographic information system) was indeed challenging during the COVID-19 pandemic as "it was the first time they came across such computer programs". When it comes to GIS, students claim that they "constantly experienced problems with the installation and functioning of the program" as they were compelled to work outside the GIS laboratory, which was located at the faculty premises. Another course that the students found difficult to attend online was the Methods in Teaching Geography because the course "demanded a practical education - a real classroom and a sense of space, geography teaching materials, pupils who would attend classes and the classroom atmosphere".

In addition, the students singled out problems with understanding practical tasks in cartography, hydrology, geomorphology, mapping, and regional and national geography.

an adequate scope and rhythm of the teaching materials. Students were burdened by concerns about their performance as they were sent too many teaching materials for different courses at the same time. What was necessary was a better timeline and coordination among the teachers. 
Even though teachers' availability was good, the manner of giving instructions to the students was not satisfactory. If distance learning remains the only option in the near future, the Google Classroom platform along with the Meet application may prove to be a better solution by providing a better interaction among students, teachers and the target curriculum. The main reason for this is that there are few verbal communication programs and the e-mail has been the dominant manner of communication, which directly affects students' activation during online courses.

Practical aspects of some courses, such as GIS, mapping, methods in teaching geography, and geomorphology, proved to be challenging for distance learning. Furthermore, online courses failed to encourage the development of spatial thinking, which should be seriously taken into consideration as spatial thinking is one of key competencies within geo-sciences. Finally, another weak point of e-learning platforms emerging from our survey is that they largely decrease social interaction and connectedness.

Final recommendations: Based on the results of the study, the following recommendations were reached in order to improve the quality of elearning at the University of Banja Luka: -Conduct a study in order to gain an insight into whether the students dispose of the technical equipment crucial for e-learning;

-Design a teacher training program in the field of e-learning methods;

-Reduce the teaching content and focus on the individual students' research tasks;

-Coordinate the rhythm and time-frame of elearning between the students and the teachers; -Focus on the interactive presentation of the teaching content through services such as Meet instead of simple submission of presentations in order to make the teaching process more efficient.

\section{REFERENCES}

[1] Bolton, David \& Smidt, Esther \& Li, Rui. Assessing the Quality of Distance Education at a University, In Ensuring Quality and Integrity in Online Learning Programs, USA, pp 149-177, 2019.

[2] Uljens, Michael. Didaktik - teori, reflektion och praktik. Studentlitteratur. Lund, Sweden, 1997.

[3] Ruutmann, Tiia. Engineering Pedagogy Science as the Contemporary Basis for Effective Teaching of Science, Technology and Engineering, Conference: Science and technology education: Current challenges and possible solutions. Proceedings of the 3rd International Baltic Symposium on Science and Technology Education (BalticSTE2019), Lithuania, 2019.

[4] KRUSE, K. The benefits and drawbacks of e-learning, 2001. (accessed 22nd October 2020).

[5] O'Donoghue, John \& Green, Charles \& Singh, Gurmak. A comparison of the advantages and disadvantages of IT based education and the implications upon students, Interactive Educational Multimedia, UK, number 9, pp 63-76, 2004.

[6] Guglielman, Eleonora. E-learning and Disability: Accessibility as a Contribute to Inclusion, Conference: Proceedings of the 5th Doctoral Consortium at the European Conference on Technology Enhanced Learning, Barcelona, Spain, pp 31-36, 2010.

[7] Yen, J. Y., Yen, C. F., Chen, C. S., Wang, P. W., Chang, Y. H., \& Ko, C. H. Social anxiety in online and real-life interaction and their associated factors, Cyberpsychology, behavior and social networking, USA, 15(1), pp 7-12, 2012.

[8] Bjekic, Dragana \& Obradovic, Svetlana \& Stojkovic, Milica \& Bojovic, Milevica. E-teacher in Inclusive eeducation for Students with Specific Learning Disabilities., Procedia - Social and Behavioral Sciences, Netherlands, 128, pp 128-133, 2014.

[9] Wang, Alvin \& Newlin, Michael. Online Lectures: Benefits for the Virtual Classroom. T.H.E. Journal, Irland, 29, 2001.

[10] Nandi, Dip \& Hamilton, Margaret \& Harland, James. Evaluating the quality of interaction in asynchronous discussion forums in fully online courses, Distance Education, Australia, 33, pp 5-30, 2012.

[11] Lee, Matthew \& Cheung, Christy \& Chen, Zhaohui. Acceptance of Internet-based learning medium: The role of extrinsic and intrinsic motivation. Information \& Management. Netherlands, 42, pp 1095-1104, 2005.

[12] Марић, Ђ и Трифуновић, М. Практикум методике наставе географије, УНИБЛ, Природно-математички факултет, Бања Лука, РС (БиХ), 2014. 